\section{Seismic Strengthening and Seismic Improvement of Timber Structures}

Maria Adelaide Parisi*

Associate Professor, Politecnico di Milano

piazza Leonardo da Vinci 32

20133 Milano, Italy

*corresponding author, e-mail: maria.parisi@polimi.it

\section{Maurizio Piazza}

Professor, Università degli Studi di Trento

Via Mesiano 77

38123 Trento, Italy

e-mail: maurizio.piazza@unitn.it

\section{Abstract}

In European seismic areas timber structures are found as building frames, in combination with masonry infills, in bridges, but most frequently in roof structures and floor slabs of traditional buildings. Seismic strengthening of existing structures should provide a well-defined and simple path to seismic forces, maintain timber members elastic, and develop as much as possible the post-elastic behaviour of joints. Provisions must be adopted to avoid sudden loss of capacity and brittle failure, and to foster ductility. Different criteria for seismic strengthening of floor slabs and of carpentry joints are presented.

Keywords: Timber structures, Seismic strengthening, Seismic Improvement, Timber floors, Timber roofs, Carpentry joints, Post-elastic behaviour

\section{Introduction}

The development or the updating of seismic zonation in a country may require reconsideration of existing structures that were built for lower levels of seismic action, or even without seismic provisions, in order to comply with current safety requirements. In Italy, for instance, the building code [1] requires that buildings undergoing major renovation or a change of use be checked also for earthquake loading. Reference is made to the seismic action to be applied in the design of new buildings. This rule aims at the progressive upgrading of the significan fraction of the building stock that was originally built without adequate consideration of seismicity. In the specific case of timber structures, plain timber sections and carpentry joints, which were the basis of traditional construction, may not satisfy the new requirements; seismic strengthening may become necessary in order to continue their use.

In Europe, the regions affected by the highest seismicity are in the south, where buildings erected completely in timber are not frequent. Yet, in traditional construction, including common buildings as well as historical architecture and monuments, timber has been used extensively to build structures for supporting floors and roofs. This chapter will focus particularly on such structures and their components.

Timber has been used since antiquity in the Mediterranean region to improve the seismic response of masonry, as witnessed by findings at archaeological sites, e.g. [2]. Different arrangements of the two materials have been developed in time, corresponding to different views of the way collaboration should be accomplished. They range, geographically and formally, from the infilled timber frames of the Pombaline architecture in Portugal, e.g. [3], through the timber framing of southern Italian "case baraccate", [4], to the timber frame-and-wall system found in Greece in the island of Leukada where a secondary frame parallels the stone masonry walls [5], again to Greece [6] and to the many solutions offered by Turkey, e.g. [7]. The close interaction between timber and masonry that is inherent in all these systems leads to their classification as composite structures rather than timber structures. Their seismic capacity may be deemed insufficient, in spite of the original intention of the builders to withstand strong earthquakes or because of reduced capacity due to damage and decay. Provisions for improving them require considering features specific to each type, e.g. [8].

Traditional full-timber buildings in many different forms and structural types are found most frequently in Turkey, both for residential use [9] and for significant religious sites [10]. Some are outstanding for their constructive boldness and beauty, like for instance the Prinkipo palace [11] at the Princess island in the Marmara sea, as shown in Fig. 1. The 6-storey high building is completely built in wood, in its main structural parts as well as in its secondary walls and partitions, and in its decorations, presenting an encyclopaedic collection of elements and techniques constructed in timber. Unfortunately, the cultural value of the Prinkipo palace and of some of these buildings was not recognized early enough and they are highly damaged. The main issue is their survival rather than their seismic resistance, which could be, in any case, attained with the criteria for interventions described here.

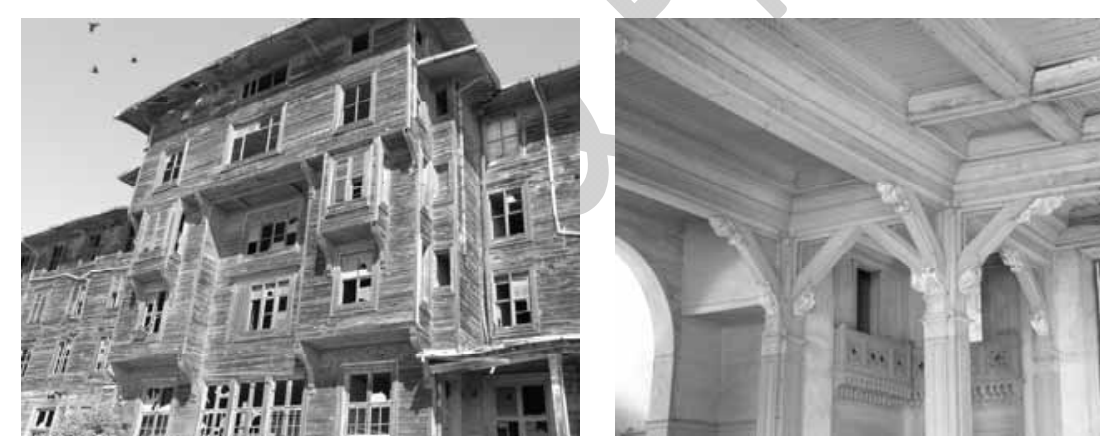

Fig. 1. The Prinkipo palace (left, the façade; right, interior view)

Bridges, which are also traditional timber structures, are present in a small number in European seismic areas and are generally considered as heritage structures. Although they may require special attention and treatment, the considerations developed in the following may be extended to their case.

Common criteria for strengthening interventions usually derive from constructional tradition. Yet, originally, strengthening methods did not address the problem of seismic response but would, rather, concern malfunctions for common vertical loads or to counter deterioration. Their effectiveness toward seismic actions needs to be confirmed.

New intervention technologies, often based on the application of advanced materials, like polymers reinforced with fibres of different kind, have been proposed also for timber structures. Some of their mechanical characteristics and easy implementation make them particularly 
appealing for strengthening existing structures. The interventions, again, must comply with criteria and requirements suitable for seismic conditions. It must be noted that in general interventions for rehabilitation or structural upgrading may be similar in the seismic and nonseismic case. In the former case, however, interventions must also adhere to principles stemming from the basic philosophy of seismic design, discussed in the following.

Often, existing timber structures belong to buildings listed as part of the cultural heritage of a country: as such, they are subjected to conservation requisites. All structural upgrading operations need to comply with criteria for restoration of heritage as well as safety. In this perspective, according to a categorization commonly used in earthquake engineering, the interventions to reduce seismic vulnerability may be distinguished between,

- $\quad$ seismic strengthening, which technically corresponds to putting the structure in the condition to withstand a design earthquake of exceptional level like a newly designed one (sometimes the term upgrading is also used), and

- $\quad$ seismic improvement, which is a milder, less invasive, and more local intervention intended to eliminate possible criticalities without implementing a general upgrading of the structural capacity to the same level as in new designs.

The approach of seismic improvement has been deemed suitable for operations on cultural heritage also by national authorities in the field [12]. Nowadays, many recent studies and observations are pointing out that less invasive interventions may yield better results even in proper seismic strengthening. In the following, the term "strengthening” will be mainly used in the more general and generic sense of structural upgrading, yet the distinction of strengthening versus improvement in the sense described above will be recalled when necessary.

In the following, general criteria are first presented; timber structures are then examined as a system and in their components, indicating which situations may be critical in seismic conditions and what interventions may be most profitably performed.

\section{Strengthening criteria}

The properties of wood as a construction material may influence the seismic response of the structure positively, because the low density generates fairly small inertia forces, and negatively because of brittleness, which is particularly marked perpendicular to the fibre/grain direction. When designing new structures, the material behaviour can be exploited optimizing the favourable contributions and providing for the drawbacks by choosing suitable structural types and details. For new timber structures, design codes and norms indicate the approach to be followed in order to obtain a suitable seismic behaviour. Basically, the current philosophy for seismic design entails exploiting post-elastic resources to an extent reasonable for the structure, depending on material, type, and construction details. For timber structures, given the very limited ductility offered by the material, wood components are designed to remain elastic Modern connections are based on the load-carrying contribution of steel connectors. Post-elastic yielding may then be developed in the joints, with contributions from steel ductility and from the embedding of timber interacting with steel.

Little or no indications are given in structural design codes for general strengthening of existing timber structures, and especially for seismic strengthening. Eurocode 8 for earthquake resistant design [13] does not refer to timber in its Part 3 , which deals with existing buildings, nor does
Eurocode 5 [14].

Yet, using as a paradigm the design of new structures, the same approach may be adopted for upgrading the existing ones. Interventions should,

supply a well-defined and simple path for seismic forces;

maintain the timber members in an elastic state, especially avoiding local stress concentrations;

- address special attention to joints, protecting them from sudden loss of capacity and brittle failure, and providing them as much as possible with post-elastic behaviour capabilities.

In this perspective, it must be considered that interventions suitable for common static loading may be inappropriate in the case of seismic action if they do not implement the basic principles of seismic design. For instance, in wood, the local increase of stiffness that may be acceptable in static situations is most often associated with a reduction of ductility, which is a fundamental property in seismic conditions.

In the last decades of the 20th century, in Italy, timber roof structures were either strongly reinforced by means of massive interventions or, more likely, removed and substituted. The new parts were usually not timber elements but industrial products fabricated with different and more massive materials. Most frequently, prefabricated concrete elements were used. The increase of mass and stiffness could be incompatible with the old and weak masonry walls underneath. In a number of cases where earthquakes arrived after strengthening, damage and even progressive collapse of the whole building took place, demonstrating the inadequacy of the works that had been performed. In the case of Fig. 2, timber trusses had been replaced with concrete trusses.

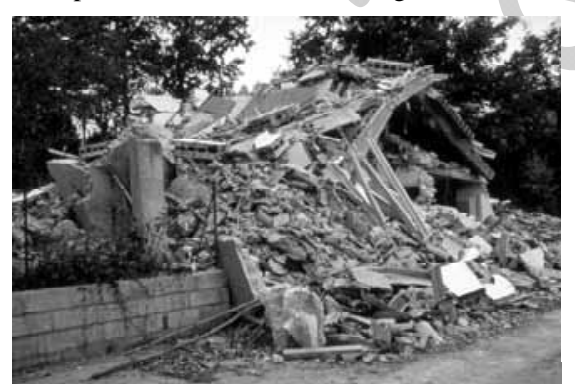

This outcome, together with a growing cultural trend recognizing the value of older construction even beyond the case of protected heritage buildings has been acknowledged in the current issue of the Italian Building Code [1], for which timber roof structures should be preferably preserved, improving their seismic behaviour by non-massive interventions when necessary. This regulation implies defining criteria for effective interventions, covering

Fig. 2. Collapse in Cesi, Umbria-Marche different possible components and situations.

Interventions on timber floor structures have also evolved with time. While timber roofs have received limited attention and only in fairly recent times, the strengthening of slabs is more established and documented. Research programs have been carried out internationally for decades and have yielded results that are now being regularly applied in practice. The strengthening of timber floors aims at increasing the mechanical properties of the slab, but keeping also in view the compatibility between the horizontal floor structure and the vertical walls system. Here again, in many cases, when the quality of masonry was particularly poor, an excessive stiffening of the slab had proven harmful for the masonry walls and the overal 
building behaviour. Research is now focusing particularly on how to increase the mechanical properties and improve the compatibility of the two systems, without introducing local irregularities and excessive strength and stiffness that may trigger failure modes; it points to offering a wide range of solutions that may fit different situations.

From the point of view of preservation of timber structures, much work has been carried out in order to guide the design of interventions on timber cultural heritage. In particular, Guidelines for interventions on wooden artefacts have been issued by UNI, the Italian Organization for Standardization as UNI 11138 [15], while a document developed as a result of a COST action, [16] offers guidance for the assessment of such structures. These documents are not specifically prepared in relation to seismic situations, but may be considered a basis for developing heritage compatible interventions in the line of seismic improvement as defined above.

\section{Problems and remedies}

The development of earthquake engineering, particularly the identification of structural problems and the proposal of solutions, has always started from the observation of seismic damage. For timber structures, however, the documentation collected in post-event recognition campaigns is usually limited to the most outstanding cases of global collapse. This may be due to the difficulty in reaching and examining the timber structures within a damaged building, but probably also to the secondary and temporary status that has always been attributed to these structures. Traditionally, timber structures have been considered to some extent provisional, and worth replacing rather than repairing whenever refurbishment or extended maintenance was due. Their role, as outlined above, is nevertheless decisive for the response.

In order to examine systematically the different causes of poor behaviour and to propose remedial or preventive interventions, timber structures may be examined as a whole system and in their components, that is, members and joints. This progression is detailed in the following for roofs and slabs, but it has a more general value and may be applied to other structural types, like timber frames, scaling down from the problems that may be inherent in the structural concept, to the state and capacity of members, and to their connections.

\subsection{The level of the structure}

Timber roof structures and floor slabs were typically built to bear vertical loads, with no provisions for responding to seismic actions in the horizontal direction. Wind on roofs, especially in southern Europe where pitch angles are low, acts mainly in suction; although it may be often destructive for inadequate structures, it widely differs in its nature and effects from the earthquake as a phenomenon.

The first aspect that should be considered is whether the structural scheme can develop equilibrium for horizontal forces. Static schemes may be insufficient because of construction errors, when elements required for horizontal equilibrium are missing, or for the presence of unrestrained thrusts that impinge on building components, like masonry walls, which are unable to supply the necessary restraint. Many old roof structures have been built by craftsmen without a formal design. In open couple roofs, depending on the detailing of supports, the rafters may apply a horizontal thrust on the walls even under vertical loads; the situation worsens and may be particularly critical when horizontal loads are also present.

In some trusses, joints with low moment transmission, close to a hinge, supply only a low rotational restraint. The resulting structural scheme is almost unstable and unfit for asymmetric loads. The low joint stiffness can accommodate some asymmetry in the vertical loads or respond to limited accidental lateral forces but collapse would very likely develop for higher horizontal forces due to an earthquake. An example of a low-stiffness joint may be seen in Fig. 3.
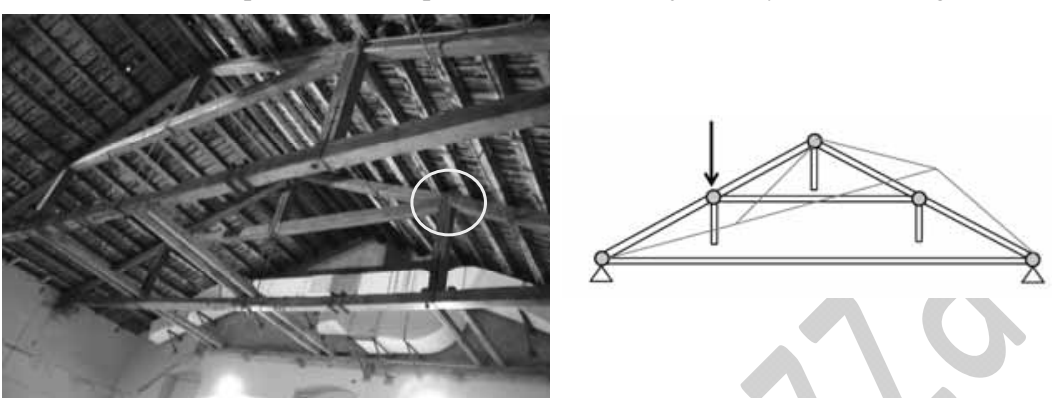

Fig. 3. Truss with low rotational rigidity joints (photo courtesy of $R$. Tomasi); depending on the joint stiffness, the structure could become unstable under asymmetric loads.

A case of a statically inadequate scheme was the 19th century roof of a church in Vimercate, Italy (Fig. 4). The structure consisted in a series of trusses interconnected by purlins and diagonal bracings. In the original structure, one truss was missing, creating a discontinuity. Additionally, from the first truss an almost horizontal bracing element pointed directly onto the façade wall in the tympanum area, inducing an extremely high risk of impinging on the most delicate area of the wall in seismic conditions.

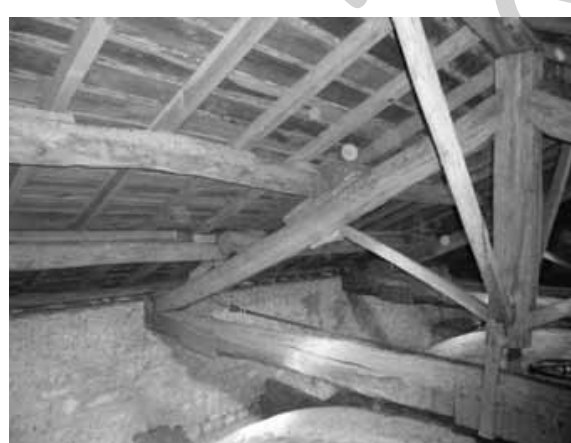

This situation, deriving from a conceptual error, not considering horizontal effects, was promptly corrected by eliminating the impinging element, separating the truss from the tympanum, and creating a different horizontal retaining system. Also, a truss was added at the proper location, reconstituting regularity in the layout.

Problems may stem also from structural schemes that are formally equilibrated in the static sense, but supply an unsatisfactory dynamic response. From the seismic point of Fig. 4. Truss with diagonal bracing element view, a robust structure should exhibit a sound (photo courtesy of C. Tardini). response in different directions of excitation.

The case of structures composed of parallel plane trusses, conceived as a bi-dimensional system, mildly interlinked to form a three-dimensional one, is very common for instance in heritage church buildings. These structures may not be sufficiently robust. Usually, timber trusses are quite stiff in their plane, but may be loosely interconnected. As a result, the roof system may be rather deformable in the direction normal to the trusses and may develop excessive displacements under seismic motion [17]. Consequently, pounding of the ridge beam into the gable wall or tympanum and collapse of the roof-wall system have often occurred (Fig. 5). 
These causes of malfunctioning due to the structure configuration are to be recognized and may be remediated, e.g. [18, 19].
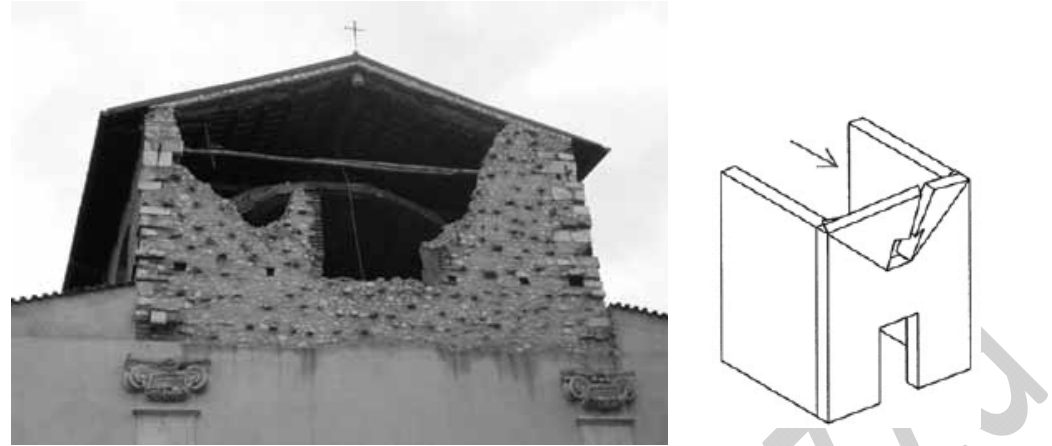

Fig. 5. Pounding of the ridge beam into the tympanum during earthquake motion may result in its collapse in a pattern similar to the above; here, other damage causes were present (S. Biagio Amiterno, L'Aquila earthquake, 2009).

A further critical point for a good seismic behaviour is the quality of the supports; even if it may not be strictly considered a problem related to timber. Roof structures falling off supports during earthquakes are not rare and often entail progressive collapse of the whole building. An effective restraint from the supports must be sought and provided as a first step in the seismic strengthening of timber roof structures.

The reinforcing of timber floors is always performed when an old building has to be rehabilitated for new use or occupancy and takes on special characteristics in the cases of seismic strengthening or seismic improvement. For vertical loads, in fact, beyond repairing possible decayed elements, the issue is usually to upgrade the flexural stiffness and capacity, e.g. [20, 21] Seismic conditions usually require raising the in-plane mechanical characteristics of the floor and improving collaboration of the horizontal structure with the vertical walls system. Caution must be exerted, because in some situations, when the quality of masonry is particularly poor, excessive stiffening and increased mass may be dangerous for the walls and the overall building behaviour. Additionally, the different redistribution of horizontal forces among walls needs be controlled, in order to avoid possible new parasitic effects from eccentricities. The question of how to attain a suitable level of mechanical properties and collaboration for the floor withou introducing irregularities and overstrength that may trigger failure modes in other elements is the subject of much study and debate at the moment. Specific conservation requirements for the original slabs in monumental buildings may also exist, limiting the choices of intervention.

In a normal case, without special limitations, it is worth considering a whole range of possibilities to achieve different levels of mechanical characteristics. A particularly effective strengthening method is the formation of a composite system associating new collaborating elements, for instance a new slab, to the existing timber structure. Substantial increase of the mechanical characteristics may be attained. In this case, the possibility of composite timberconcrete structures and of timber-timber structures offers two groups of solutions, each producing a range of mechanical properties for the floor structure depending on the type of connection adopted, e.g. $[22,23,24,25]$. A main difference is in the use of dry or grouted

connectors and in the shape and distribution of these elements, usually in steel, that have the task of consolidating the beams with the newly produced slab. Grouting with resins forms a very efficient connection, but may have some inconveniences, particularly in terms of restoration issues.

A fully functioning connection should provide full cooperation with the slab augmenting the beam cross-section into a T-shape. Yet, collaboration is always partial, to a more or less extended degree. In all cases, an efficient connecting system is the key to obtain a favourable behaviour.

Fig. 6 shows some examples for a timber-concrete composite structure.

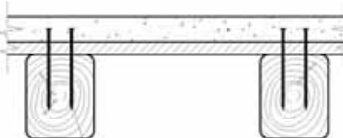

Self tapping screws

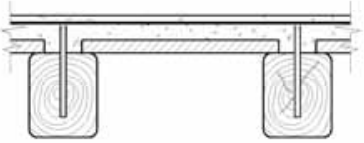

Welded steel mesh

Concrete slab

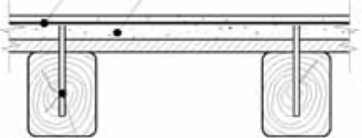

Metallic connectors

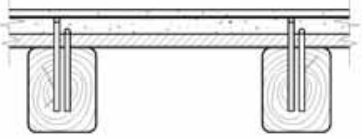

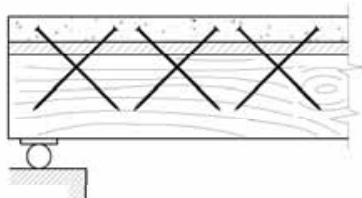
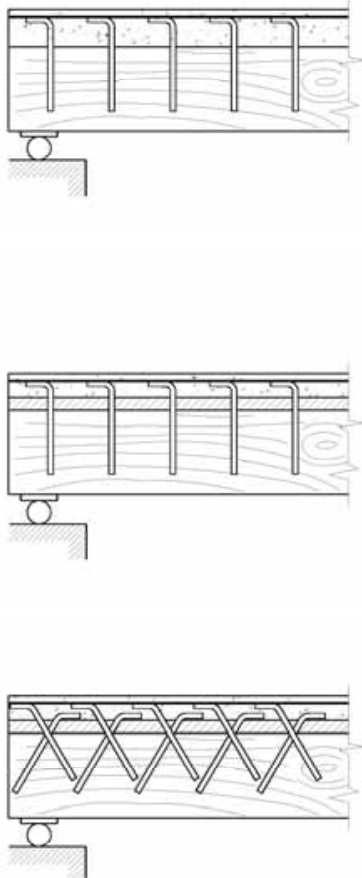
Timber plank
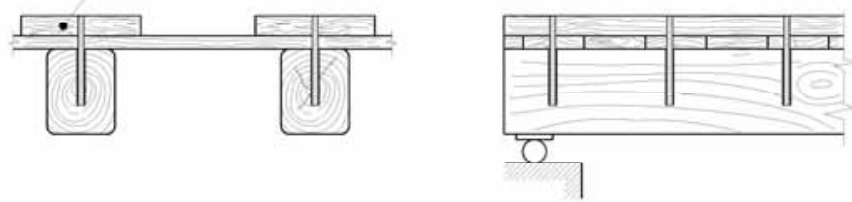

Plywood
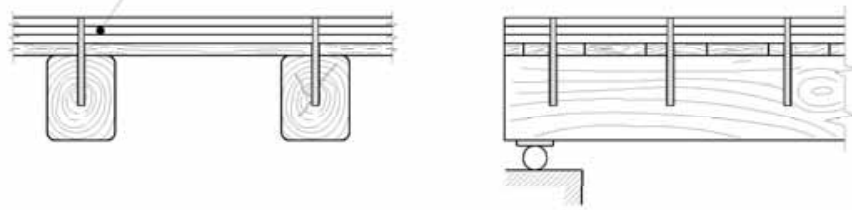

- -2
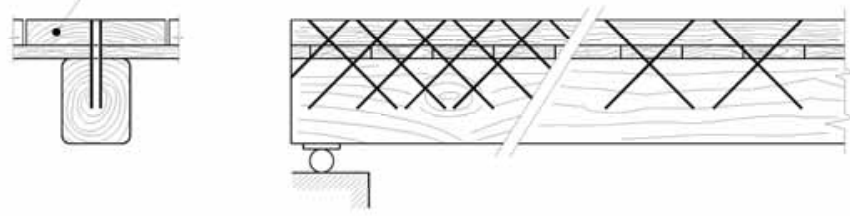

Fig.6. Glued-in connectors, with various arrangement, used for assembling timber - concrete composite structures

Recent research programs have proposed various solutions particularly in view of improving the in-plane behaviour. Besides the addition of a concrete slab, or of a timber slab in the cross-wise direction, the application of a lattice of FRP tapes, or of metal bands has been examined, in order to acquire stiffness without excessive material addition, as shown in Fig. 7. Cross laminated timber (CLT) toppings are not represented in the figure, considering that a CLT slab, not very thin, may not be able to adhere properly to an existing, usually sagged beam.

Experimental apparatuses have been set up for in-plane testing of floor slabs in a reduced scale as well as in full scale (Fig. 8), also assessing the small scale effect, by different research groups, e.g. [26, 27, 28, 29, 30, 31, 32, 33, 34]; numerical models have been calibrated for slabs with different reinforcement based on experimental results. The final purpose of these studies is to evaluate the effects of the in-plane stiffness reached by different strengthening criteria (Fig. 9) on the capacity curve of a traditional masonry building. This may be evaluated numerically, by a nonlinear static (pushover) analysis. Case studies are being carried out to this purpose [35, 36].

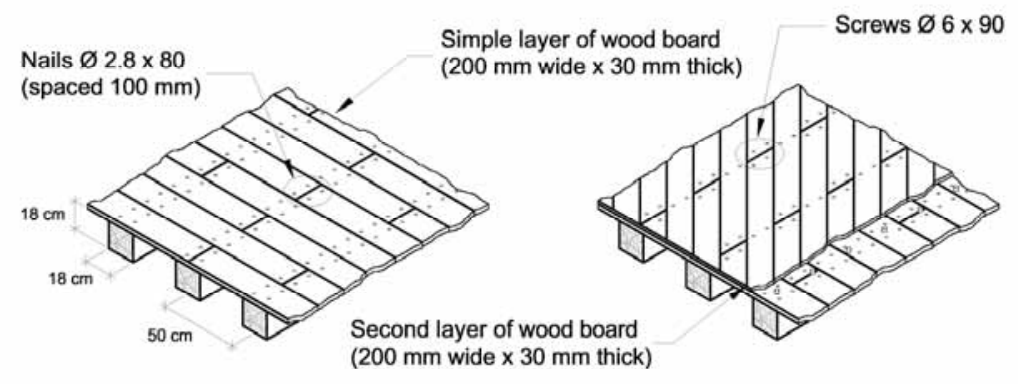

(a)

(b)

Epoxy resin (Mapei Adesilex)

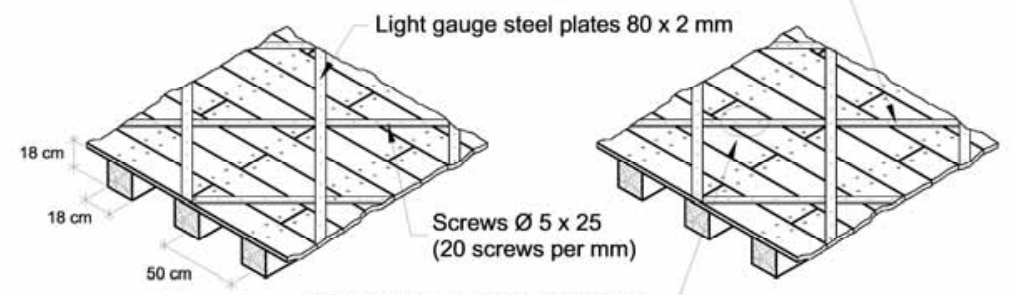

CFRP strips (Mapei Carbonplate)

(c)

(d)

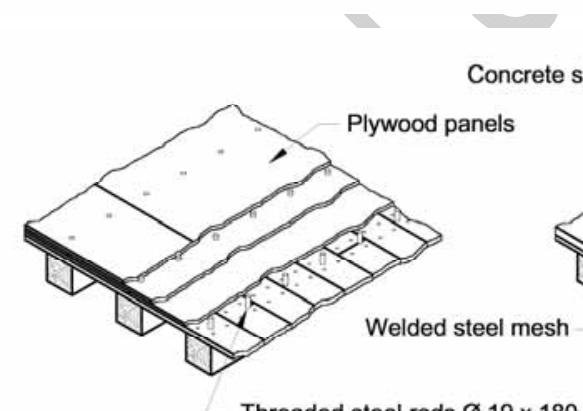

(e)

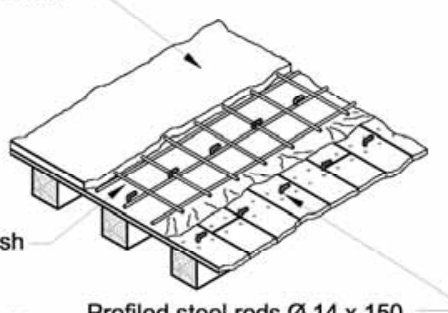

Profiled steel rods $\varnothing 14 \times 150$

(f)
Fig. 7. Different timber floor in plane shear strengthening techniques: (a) existing simple layer of wood planks on the timber beams; (b) second layer of wood planks arranged crosswise on the existing one and fixed with steel screws; (c) diagonal bracing of the existing wood planks by light gauge steel plates; (d) diagonal bracing of the existing wood planks by FRP laminae; (e) light gauge steel plates; (d) diagonal bracing of the existing wood planks by FRP laminae; ( $e$ )
three layers of plywood panels glued on the existing wood planks; ( $f$ ) a reinforced concrete slab connected by means of studs (all measures in $\mathrm{mm}$ ) [26]. 

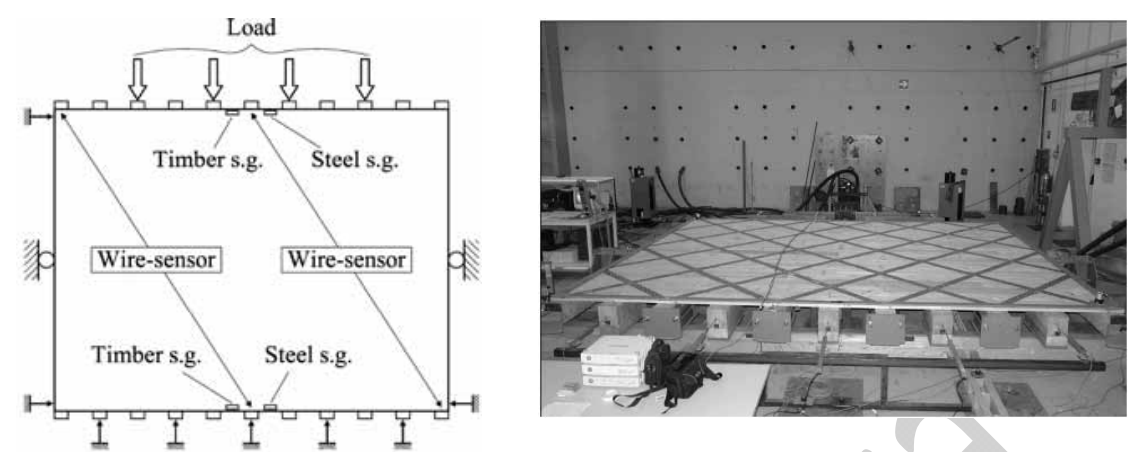

Fig. 8. Scheme of an experimental apparatus for in-plane testing of slabs, and an example; s.g. indicates the strain gage positions [26].

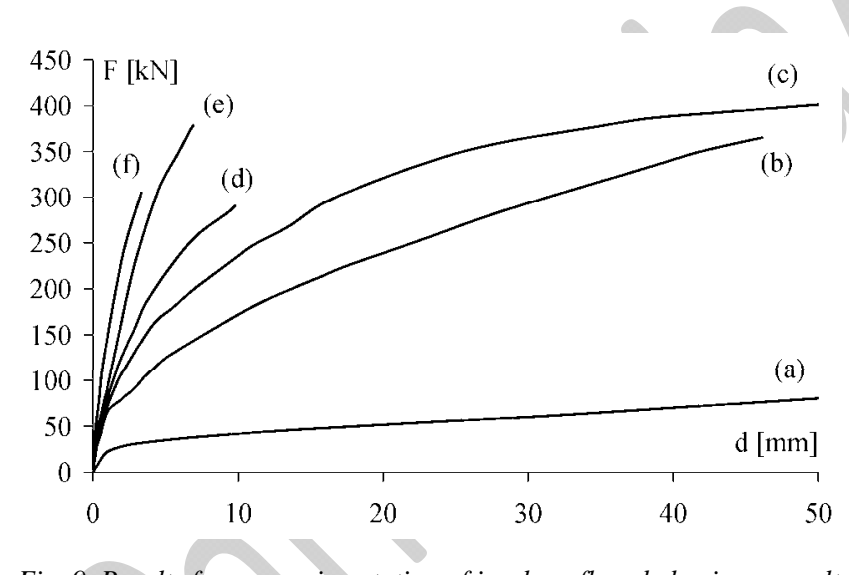

Fig. 9. Results from experimentation of in-plane floor behaviour: resultant force versus midspan displacement. (a) existing simple layer of wood planks, (b) second layer of wood planks, (c) diagonal bracing with light gauge steel plates, $(d)$ diagonal bracing with FRP laminae, $(e)$ three layers of plywood, $(f)$ reinforced concrete slab [26].

On the basis of these studies, some general indications for strengthening, at the level of the structure, may be given, as follows, even if it must be pointed out that each case shall be often regarded as a specific case study;

- The structural behaviour of the building as a whole must be enhanced, improving the inplane behaviour of the slabs (floors and roofs) and their connections with masonry walls. This should be obtained without excessive stiffness concentration, and without any increase of the mass, thus the solutions b), c) d) and e) of Fig. 7 seem to be more advisable;

- The supports of timber members belonging to floors and roofs must be accurately checked and strengthened if necessary, assuring bi-lateral connections between the elements and the walls, disregarding any contribution of friction between wood and masonry;

- The presence of unrestrained thrusts from rafters and other timber elements impinging on walls must be avoided and, if this is not possible, timber elements must be added in order to reconstitute the regularity of structural layout;

- $\quad$ Each joint must be able to maintain elements in contact, avoiding possible disassembling of the joint under exceptional actions, as discussed hereafter.

3.2 The level of the elements

In the general strengthening of a building it is often necessary to improve the state of timber elements that may present section reductions due to decay or even to insufficient original crosssections in relation to the higher stress level in seismic conditions.

Damage often occurs at the extremes of the beams, where the shear force is at its maximum and where the beam, snugly constrained in the wall, suffers limited air circulation that favours wood moisture contents above $20 \%$ and, as a consequence, the development of biotic attack. It is usually necessary to eliminate the damaged part and replace it with new material, ensuring collaboration between the new and the original part, in order to restore full continuity of mechanical properties. Different methods may be adopted. The additional material may be either embedded in the wood and connected to it in order to reconstitute the original section, or may be added as a new element beside the first one, e.g. [37], (Fig. 10). The second approach is particularly useful to increase the original section size and consequently the original mechanical properties, therefore its major use is in the strengthening of floor systems. It must be considered that often these interventions are required for heritage buildings for which conservation rules are enforced. In this case the addition of material that remains visible may not be acceptable.
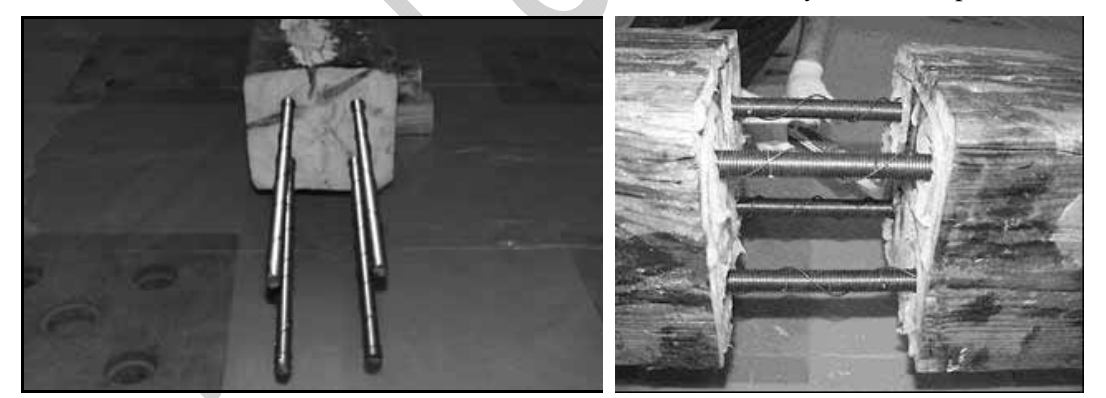

Fig. 10. Fabrication of specimens with glued-in steel rods [37].

If following the first option, the two parts may be joined by inserting glued steel bars across the discontinuity, as done in some connections for new wood-based materials like glued laminated timber, for which abundant literature is available. The approach offers several advantages when adopted in existing structures to improve mechanical properties or restore continuity: a high connection stiffness without significant settling; the possibility of ductile design with yielding of the steel, in spite of the adherence based on glue; the protection of glue and of the embedded steel elements from chemicals and fire (a positive feature that is not shared by other techniques using external materials, for example those with polymeric matrix); on the non-structural side, 
the unmodified exterior of the reinforced element, that maintains the original aspect.

The method is still affected by uncertainties and difficulties and is currently receiving attention by several researchers. Among the possible drawbacks is the elastic-brittle contribution that the connection of timber-glue-steel may give to the global behaviour of the section. Besides, suitable glues must be specified for the job according to the expected service conditions, particularly under steady high service temperatures [38, 39]. Timber elements are not considered dissipative, yet an acceptable level of ductility must be ensured. An additional question to be clarified concerns the stresses induced by the dimensional changes of wood due to moisture variations.

The load bearing capacity of the connection is limited by failure modes concerning pull-out: namely,

a) pull-out of the steel element due to cohesive failure in the glue or in the wood, adhesive failure in the glue-steel or glue-wood interfaces, or cohesive failure at the adhesive-wood fibres interface;

b) splitting failure of wood caused by excessive tensile stresses perpendicular to the grain;

c) shear failure of wood (plug-type failure).

If the metal surface is rough, as in the case of threaded or ribbed bars, the adhesive failure at the glue-steel interface will not occur; yet a good glue-steel adhesion is far more difficult to achieve when the steel surface is large, like in the case of plates. The other modes are not always physically distinguishable, since the pull-out of steel and the transversal splitting of the timber element most often occur simultaneously.

The same connections may be constructed by substituting steel bars with fibre reinforced polymeric materials (FRP) for which similar remarks apply. FRP plates are proposed also for the upgrading of properties in timber beams: plates may be glued externally on the tension side or inserted and glued-in along the length, a solution that protects the material and is more compatible with requirements related to visual aspects e.g. [40]. An important research effort is, indeed, devoted to FRPs and their use in timber structures.

As a general remark, in spite of the effectiveness offered by the connection with glued-in elements, the presence of glue in the assembly may introduce some amount of brittleness. Considering the general philosophy in the seismic design or seismic strengthening of timber structures that bans any brittle contribution from the areas where different timber members are joined, as discussed in a further section, these glued-in inter-element connections should be kept far from the joint areas, positioning them where the timber elements remain elastic.

Also at the level of the elements, some general indications may be given, as follows:

- When it is necessary to eliminate the damaged part of an element, it is better to replace it with a timber prosthesis, possibly of the same species, connecting the two parts by means of glued-in steel rods; as a general remark, this kind of connection may introduce brittleness, so glued-in inter-element connections should be kept far from the joint areas;

Glued-in steel or FRP rods may be used for improving the mechanical performance of timber elements; the best results, also in terms of durability of the intervention, can be obtained with elements inserted into the element, rather than with elements glued externally.

\subsection{The level of joints}

A peculiarity of timber structures, both new and old, is the essential role of connections in determining a successful behaviour of the whole structural system. For structures built according to current design practice, joints are usually fabricated with metal connectors that undertake the transmission of loads between timber elements; for ultimate conditions they may be dimensioned to develop a ductile post-elastic behaviour of the joint exploiting proper interaction with the wood. Considering the very limited post-elastic resources of timber, joints become the only possible location of post-elastic yielding and of energy dissipation.

In traditional timber structures, carpentry joints are suitably shaped in order to transmit forces by direct contact and friction. Their many forms encompass a wealth of heuristic knowledge passed on by generations of carpenters. Traditionally, metal devices, when present, were mainly meant to prevent accidental and unexpected misalignment of parts, avoiding disassembling of the joint under exceptional loads without acting in normal working conditions, according to a robust conception of the joint. Here again, joints were the critical elements for the safety of the whole structural system. It is worth noting that old metal connectors already present in a joint may not comply with current safety requirements and must always be checked.

Seismic design codes offer little or no indications for strengthening or improving carpentry joints. Interventions are mostly performed according to traditional criteria, which are usually more related to static conditions.

In order to express criteria for seismic strengthening, the two working conditions of a joint, that is, the normal service conditions and the limit state in response to exceptional actions, may be assumed as reference. Since codes give no guidance for existing joints, it is convenient, once more, to refer to the principles expressed for the design of new timber structures, for which the structural capability of post-elastic cyclic deformations and of energy dissipation concentrates in the connections, while timber elements must remain elastic. Table 1 defines requirements for joints in the two reference states.

Table 1. Performance requirements for carpentry joints

\begin{tabular}{ll}
\hline State & Goals of the connection \\
\hline Service conditions & 1. transmit forces by contact \\
Ultimate conditions & 2. avoid joint disassembly \\
& 3. avoid brittle failure modes \\
& 4. enhance ductility/ energy dissipation \\
\hline
\end{tabular}

Experimental research programs have been carried out over several years to assess the elastic and post-elastic behaviour of the main types of carpentry joints traditionally used in roof trusses. Extended programs were conducted in Italy $[41,42,43,44]$, in Portugal, with similar results [45, 46, 47], and in Belgium [48, 49]. One important objective has been to devise reinforcement criteria that would be effective especially in extreme conditions, but would not change the original way of functioning of the connection for normal loading situations. The main idea has been to account for the conservation of cultural values and at the same time provide safety and develop in a modern sense the characteristic of robustness implicit in tradition. Only metal devices, which are the most traditional kind of reinforcement, have been considered, 
disregarding more innovative but less common fibre reinforced materials. The research work has treated particularly the step or cogging joints used in the rafter-to-chord node and in other connection areas of trusses, characterizing the mechanical behaviour in monotonic and cyclic conditions and comparing different types of reinforcement. Fig. 11 shows the testing apparatus with a full-scale specimen of a rafter-to-chord node reinforced with a binding strip. A constant pressure is applied to the rafter, while a variable transversal force acts at its upper end, rotating it. The objectives of the program were: 1 ) to quantify the joints rotational stiffness in the elastic range, that is, in service conditions, as a function of the main joint parameters, like geometry and compression level, in order to develop accurate semi-rigid models; 2) for the post-elastic range, to investigate the effect of the different types of reinforcement and repair/strengthening with particular attention to the capability to withstand an adequate number of load cycles, and to point out situations that could trigger brittle failure modes.
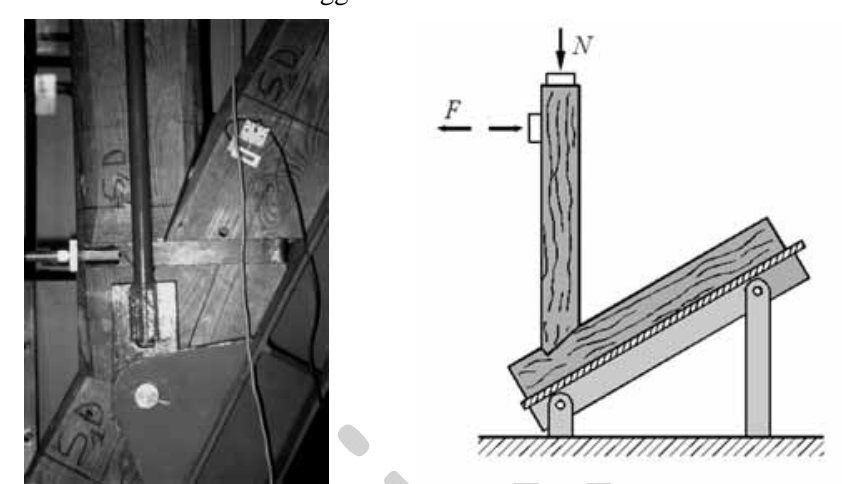

$$
\text { Dry }
$$

Fig. 11. Experimental setup with a specimen of rafter-to-chord node [43].

Other joints considered in research programs have been the double step joint, used for large rafters and chords with a double notch in the chord, the scarf joint, which is usually present in truss chords composed of two segments and having a characteristic zigzag shape, the half-depth lap joint, typically connecting cross-bracing elements (Fig. 12), the dovetail joint [43, 50, 51, 52, $53,54,55]$, and the tenon-and-mortise joint [56, 57].

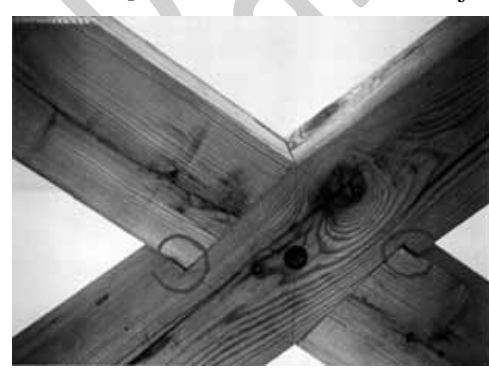

Some interesting works in the literature deal with connections used in the far eastern carpentry tradition, although the work is usually not focused on seismic response or strengthening issues $[58,59,60$, 61].

On the basis of these studies, some indications for strengthening interventions may be given, as follows:

Fig. 12. Half-depth lap joint [45].

Traditional carpentry joints transmit forces between connected elements by contact and friction; yet, contact pressure may be reduced in seismic or other exceptional conditions; contact may be decreased or even eliminated also by unexpected out-of-plane forces; metal connectors must be applied to prevent disassembly, yet they should not alter the working modality in normal conditions; in particular, the connection stiffness should not be significantly increased; the strengthening interventions should not induce parasitic effects like over-stiffening; in particular the relative rotational capacity between connected members should not be drastically reduced or eliminated;

- In limit conditions, post-elastic capacity should be enhanced and brittle failure should be avoided; to this end, care must be taken to avoid introducing brittle modes of failure in the timber or metal elements;

- Because brittleness may be introduced by glue, gluing is not admitted in the joint area; connection of prostheses to the repaired timber member by means of glued-in stee elements should be performed away from the joint area;

- Similarly, the use of metal connectors with welded parts should be avoided as a possible cause of brittleness;

- Particularly in the rafter-to-chord node of a truss, the use of metal cages or cuffs containing the joint may cause brittle behaviour in the timber elements and induce uncontrolled decay by forming an adverse microclimate in the node area (Fig. 13);

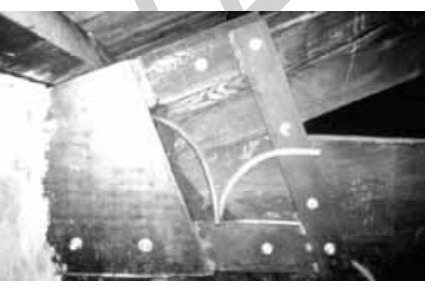

8

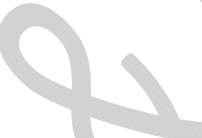

Fig. 13. Encapsulated joint [62].

- Brittle behaviour may also result more subtly from placing a relatively small amount of reinforcement with an inappropriate layout, preventing relative rotation of the elements; in the cases presented in Fig. 14, the best results can be obtained by reinforcing the carpentry connection with two transversal bolts of small diameter (Fig. 14, left);

- Brittle failure modes may occur at critical locations like the chord toe of a rafter-to-chord node that is also particularly prone to biotic attack. The toe may fail in sliding shear due to the horizontal force from the rafter, especially for low connection angles, short toe length (and timber with biotic attack). The reduced section of the rafter tip may also fail by compression; evenly distributing small diameter connectors, like screws, in these areas should eliminate or control the problem (see Fig. 15); as a dimensioning indication, at the toe, the total amount of steel should be able to carry the shear force without relying on the timber. 


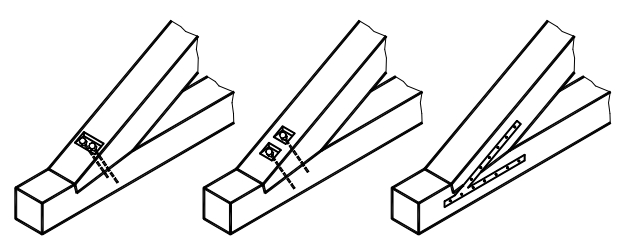

Fig. 14 Connection reinforced with two transversal bolts of small diameter (left) gave the most satisfactory cyclic behaviour.

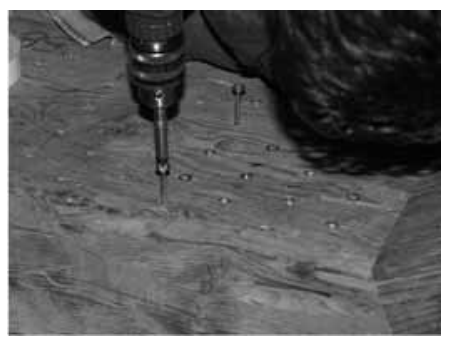

Fig. 15 Distributed reinforcement to prevent brittle failure, using fully threaded self-tapping screws or glued-in steel rods.

\section{Effectiveness of interventions}

In order to assess the effectiveness of strengthening interventions in the seismic field, both experimentation and numerical analysis may be used. Given the difficulties and often the impossibility to perform dynamic tests, the limitations that are encountered in developing accurate models of the structure or element, and the uncertainties intrinsic in the seismic action, neither of the two approaches, supplying a partial view of the situation, may fully confirm the validity of a solution, but each may point out particular advantages or criticalities.

Numerical analysis is a powerful tool for assessing the level of seismic response of a structure, as long as modelling has been accurate, which may be at times problematic especially with old structures. Nevertheless, much information may be obtained from both static and dynamic analysis of the global configuration, and from fine modelling of details.

Research projects with extended experimental campaigns, like those quoted above on joints, have permitted the comparison of different strengthening interventions in the static and in the cyclic field, extended to the nonlinear behaviour, that is, to ultimate conditions.

Experimentation on full-scale trusses, with spans ranging from 12 to $24 \mathrm{~m}$, after their carpentry joints had been reinforced according to the methods tested, have given information on the global behaviour in symmetric and anti-symmetric static loading conditions. Numerical analyses of the same trusses and of other structures have been performed with an accurate modelling of the behaviour of the strengthened joints calibrated with experimental results, in order to investigate the dynamic and seismic response of the upgraded structure. Behaviour factors around 3 have resulted from seismic time-history analyses, confirming the possibility of good post-elastic response after strengthening interventions.

The behaviour of timber elements before and after a strengthening intervention has been determined experimentally; in particular, results are available for beams supporting floor slabs e.g. $[63,64,65]$.

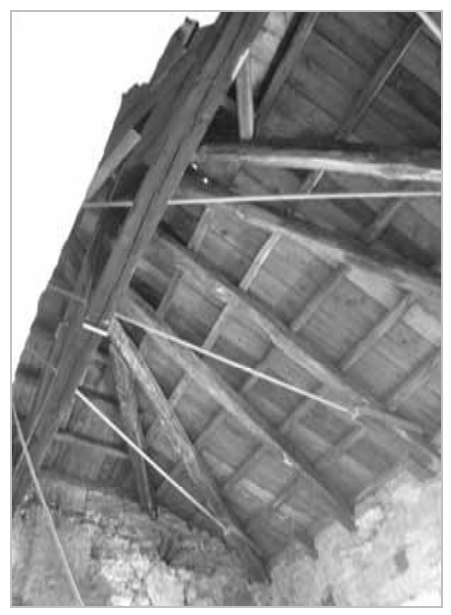

Fig. 16. Roof system reinforced with steel ties [66].

\section{Conclusions}

In European seismic areas timber structures are mainly present to support roofs and floor slabs. These elements were originally conceived for vertical loads, therefore interventions to upgrade their seismic response are often required.

In planning interventions for the seismic strengthening or improvement of timber roof structures, the structure should be first examined to detect possible construction errors, like rafters not restrained by chords and applying thrusts on the supporting walls, or missing elements in general; it must be ensured that the static scheme can respond to horizontal actions, and that stiffness, and therefore deformability, is comparable in the main directions.

Excessive increase in the mechanical parameters, and especially of stiffness, should be avoided. This precaution should be applied to the structure, to the repair and strengthening of individual members, and particularly, at a local level, to carpentry joints, that are a leading element in the system response. With reference to exceptional earthquake conditions, the goals of interventions on carpentry joints are to avoid brittle failure modes, which may result from the original layout or may be consequent to an increase of stiffness, to foster the deformational capability in the post-elastic field, and to prevent disassembly, which is attained by inserting suitable metal connectors. The joints, however, should maintain their original working modality in common service conditions, that is, transmit forces by direct contact, without contribution from the connectors.

Similar recommendations hold for slab structures. Interventions increasing the in-plane stiffness are particularly interesting in the seismic field because the resulting structure will interact with masonry walls affecting the horizontal force distribution and, therefore, the system response. Here again, beyond the most common case of collaborating concrete slab, different solutions are being studied to offer a variety of mechanical properties among which to choose the most appropriate for the context. a function of the type of reinforcement have been and are being tested by different groups in Europe and analyses of the seismic response of the wall-floor systems, are giving interesting information on the Lastly, some cases of positive behaviour have been ( where minimally invasive and low-mass f example approach [e.g. 66]. 


\section{Acknowledgement}

This article was first published in "Reinforcement of Timber Structures. A state-of-the-art report". Ed. A. Harte, P. Dietsch, Shaker Verlag, 2015.

Support received from DPC-ReLUIS Projects 2010-13, 2014 and 2015 is gratefully

acknowledged.

\section{References}

[1] D.M. 14.01.2008, Nuove norme tecniche per le costruzioni, G.U. 4.02.2008, n.29, Ministero delle Infrastrutture, dell'Interno e Dipartimento Protezione Civile, Roma, 2008.

[2] Tsakanika, E., "The constructional analysis of timber load bearing systems as a tool for interpreting Aegean Bronze Age Architecture”, in: Proceedings of Bronze Age Architectural Traditions in the Eastern Mediterranean: Diffusion and Diversity, Munich, Germany, 2008, pp. 127-139.

[3] Monteiro, M, Lopes, R., Bento, R., "Dynamic behaviour of a Pombalino quarter”, in: Proceedings of Conference for the 250th Anniversary of the 1755 Lisbon Earthquake, Lisbon, 2005.

[4] Ruggieri, N., Tampone, G., Zinno, R., "Typical Failures, Seismic Behaviour and Safety of the "bourbon system" with timber framing", Advanced Materials Research, Vol. 778, 2013, pp. 58-65.

[5] Vintzileou, E., Zagkotsis, A., Repapis, C., and Zeris, C, "Seismic behaviour of the historical system of the island of Lefkada, Greece”, Construction and. Building Materials, Vol. 21, No.1, 2007, pp. 225-236.

[6] Vintzileou, E., "Effect of Timber Ties on the Behavior of Historic Masonry", Journal of Structural Engineering ASCE, Vol. 134, No. 6, 2008, pp. 961-972.

[7] Gülkan, P., Langenbach, R., "The earthquake resistance of Traditional timber and Masonry Dwellings in Turkey", in: Proceedings of 13th World Conference on Earthquake Engineering, Vancouver, Canada, 2004.

[8] Poletti, E., Vasconcelos, G., "Seismic behaviour and retrofitting of timber frame walls", Advanced Materials Research, Vol. 778, 2013, pp. 706-713.

[9] Arun, G., “Traditional timber construction in Turkey”, in: Proceedings of Intl. Symposium "Timber structures from antiquity to the present", T.C. Haliç University Press, Istanbul, 2009, pp. 113-124.

[10] Demir, A., "Wooden-columned mosques in Anatolia”, in: Proceedings of Intl. Symposium "Timber structures from antiquity to the present", T.C. Haliç University Press, Istanbul, 2009, pp. 15-26.

[11] Somer, M.E., "Prinkipo Palace”, in: Proceedings of Intl. Symposium "Timber structures from antiquity to the present”, T.C. Haliç University Press, Istanbul, 2009, pp. 371-382.

[12] DPCM 26.02.2011, Linee Guida per la valutazione e riduzione del rischio sismico del patrimonio culturale con riferimento alle norme tecniche per le costruzioni, (Guidelines for risk evaluation and reduction of the cultural heritage, in Italian, by the Ministry of Cultural Heritage, MiBACT), G.U. 26.02. 2011 n.47, Roma, 2011.
[13] EN 1998-1, Eurocode 8: Design of structures for earthquake resistance. Part 1: General Rules, Seismic Actions and Rules for Buildings, CEN, European Committee for Standardization, 2004, Brussels, Belgium.

[14] EN 1995-1, Eurocode 5: Design of timber structures. Part 1-1: General rules and rules for the buildings, CEN, European Committee for Standardization, 2005, Brussels, Belgium.

[15] UNI 11138, Cultural heritage - Wooden artefacts - Building load bearing structures Criteria for the preliminary evaluation, the design and the execution of works, UNI, (English version: 2004), Milano.

[16] Cruz, H., Yeomans, D., Tsakanika, E., Macchioni, N., Jorissen, A., Touza, M., Mannucci, M., Lourenço P. B., "Guidelines for the On-Site Assessment of Historic Timbe Structures", Intl. Journal of Architectural Heritage, 2013, DOI: 10.1080/ 15583058.2013.774070.

[17] Parisi, M.A., Chesi, C., Tardini, C., "Inferring seismic behaviour from morphology in timber roofs", International Journal of Architectural Heritage, Vol. 6, 2012, pp. 100-116.

[18] Parisi, M.A., Piazza, M., "Restoration and Strengthening of Timber Structures: Principles, Criteria, and Examples", Practice Periodical on Structural Design and Construction ASCE, Vol. 12, No. 4, 2007, pp. 177-185.

[19] Giuriani E., Marini A., "Wooden roof box structure for the anti-seismic strengthening of historic buildings”, Journal of Architectural Heritage, Vol. 2, No. 3, 2008, pp. 226-246.

[20] Giongo, I., Piazza, M., Tomasi, R., “Out of Plane Refurbishment Techniques of Existing Timber Floors by means of Timber to Timber Composites Structures", in: Proceedings of 12th World Conference on Timber Engineering, Session 45, Auckland, New Zealand, 2012, pp. 544-550.

[21] Giongo, I., Piazza, M., Tomasi, R., "Cambering of timber composite beams by means of screw fasteners”, Wiadomosci Konserwatorskie - Journal of Heritage Conservation, Journal of the Association of Monument Conservators, Vol. 32/2012, 2012, ISSN 08602395, pp. 133-136.

[22] Piazza, M., "Restoration of timber floors via a composite timber-timber solution", in: Proceedings of the Technical Workshop RILEM Timber: a Structural Material from the Past to the Future, Trento, 1994, pp.167-187.

[23] Tomasi, R., Crosatti, A., Piazza, M., "Theoretical and Experimental Analysis of Timber-toTimber Joints connected with inclined Screws", Construction and Building Materials, Vol. 24, 2010, pp.1560-1571.

[24] Piazza, M., Polastri, A., Tomasi, R., "Ductility of timber joints under static and cyclic loads", in Proceedings of the Institution of Civil Engineers. Structures and Buildings, Vol. 164, No. SB2, 2011, pp. 79-90.

[25] Giongo I., Piazza M., Tomasi R., "Investigation on the self-tapping screws capability to induce internal stress in timber elements”, Advanced Materials Research, Vol. 778, 2013, pp 604-611, Trans Tech Publications.

[26] Piazza, M., Baldessari, C., Tomasi, R., "The role of in-plane floor stiffness in the seismic behaviour of traditional buildings", in: Proceedings of the 14th World Conference on 
Earthquake Engineering, Beijing, 2008.

[27] Filiatrault, A., Fischer, D., Folz, D. Uang, C-M., "Experimental parametric study on the inplane stiffness of wood diaphragms", Canadian Journal of Civil Engineering, Vol. 29, 2002, pp. 554-566.

[28] Paquette, J., Bruneau, M., Brzev, S., "Seismic Testing of Repaired Unreinforced Masonry Building having Flexible Diaphragm”, Journal of Structural Engineering ASCE, Vol. 130, No. 10, 2004, pp. 1487-1496.

[29] Giuriani E., Marini A., Plizzari G., "Experimental behaviour of stud connected wooden floors undergoing seismic action”, Restoration of Building and Monuments. Vol.11, No.1, 2005, pp. 3-24.

[30] Corradi, M. Speranzini, E., Borri, A. \& Vignoli, A., "In-plane shear reinforcement of wood beam floors with FRP”, J. Compos Part B, Vol. 37, 2006, pp. 310-319.

[31] Baldessari, C., Piazza, M., Tomasi, R., "The refurbishment of existing timber floors: characterization of the in-plane behaviour", in: Proceedings of PROHITECH 9 Protection of Historical Buildings, Taylor \& Francis, London, 2009, pp. 255-260.

[32] Brignola, A., Pampanin, S., Podestà, S., "Experimental Evaluation of the In-Plane Stiffness of Timber Diaphragms”, Earthquake Spectra, Vol. 28, No. 4, 2012, pp. 1687-1709.

[33] Giongo, D. Dizhur, R. Tomasi, J. Ingham, "In-plane assessment of existing timber diaphragms in URM buildings via quasi-static and dynamic in-situ tests", Advanced Materials Research, Vol. 778, 2013, pp 495-502.

[34] Wilson, A., Quenneville, P. J. H., Ingham, J. M., “In-plane orthotropic behavior of timber floor diaphragms in unreinforced masonry buildings", Journal of Structural Engineering ASCE, Vol. 140, No. 1, 2014, pp. 04013038-1-11.

[35] Giongo I., Piazza M., Tomasi R., "Pushover analysis of traditional masonry buildings: influence of refurbished timber-floors stiffness", Paper no. 51, in: Proceedings of SHATIS'11 Intl Conference on Structural Health Assessment of Timber Structures, Lisbon, Portugal, 2011.

[36] Giongo, I., Piazza, M. Rizzardi, A., Rodegher, C., Tomasi, R. "Seismic evaluation of URM buildings with flexible diaphragms. Proposal of a simplified 'ENT' method", Paper no. 2629, in: Proceedings of 15th World Conference on Earthquake Engineering, Lisbon, Portugal, 2012.

[37] Piazza, M., Parisi, M.A., "Rehabilitation of timber structures by new materials and connectors", in: Proceedings of 10th Conf. "Structural faults \& repair 2003 - Extending the Life of Bridges, Concrete \& Composites, Buildings, Masonry \& Civil Structures", Commonwealth Institute, London, 2003.

[38] Custodio, J., Broughton, J. \& Cruz, H., "Rehabilitation of Timber Structures - preparation and environmental service condition effects on the bulk performance of epoxy adhesives", Construction and Building Materials, vol. 25 (8), 2011, pp.3570-3582.

[39] Custodio, J., Broughton, J. \& Cruz, H., "Rehabilitation of Timber Structures -Novel test method to assess the performance and durability of bonded-in rod connections", Materials and Structures, vol. 45, (1-2), 2012, pp. 199-221.
[40] Borri A, Corradi M, Grazini A., "A method for flexural reinforcement of old wood beams with CFRP materials”, J. Compos Part B, Vol. 36, No. 2, 2005, pp.143-53.

[41] Parisi, M.A., Piazza, M., "Mechanics of plain and retrofitted traditional timber connections”, Journal of Structural Engineering ASCE, Vol. 126, No. 12, 2000, pp 13951403.

[42] Parisi, M.A., Piazza, M., "Seismic Behavior and Retrofitting of Joints in Traditional Timber Roof Structures”, Soil Dynamics and Earthquake Engineering, Vol. 22, No. 9-12, 2002, pp 1183-1191.

[43] Parisi, M.A., Piazza, M., "Seismic strengthening of traditional carpentry joints", in: Proceedings of the 14th World Conference on Earthquake Engineering, Beijing, 2008.

[44] Parisi, M.A., Piazza, M., “Carpentry Joints in Earthquake Conditions”, Ingegneria Sismica- International Journal of Earthquake Engineering, Vol. 4, 2013, pp. 55-72.

[45] Palma, P., Cruz, H., "Mechanical behaviour of traditional timber carpentry joints in service conditions - results of monotonic tests", in: Proceedings of the XVI International ICOMOS IWC Symposium "From material to Structure - Mechanical behaviour and failures of the timber structures”, Venice, Italy, 2007.

[46] Branco, J.M., Piazza, M., Cruz. P.J.S., "Experimental evaluation of different strengthening techniques of traditional timber connections”, Engineering Structures, Vol. 33, 2011, pp. 2259-2270.

[47] Palma, P., Garcia, H., Ferreira, J., Appleton, J., Cruz, H., "Behaviour and repair of carpentry connections - Rotational behaviour of the rafter and tie beam connection in timber roof structures”, Journal of Cultural Heritage, Vol. 13, No. 3, Supplement: S, 2012, pp. S64-S73.

[48] Descamps T., Lambion J., Laplume D. (2006), “Timber Structures: Rotational stiffness of carpentry joints”, in: Proceedings of World Conference on Timber Engineering, Portland, USA, 2006

[49] Descamps T., Noël J., Semi-rigid analysis of old timber frames: definition of equivalent springs for joints modeling. Enhancement of the method, numerical and experimental validation. International Review of Mechanical Engineering. Vol. 3, No. 2, 2009, pp 230239.

[50] Bulleit, M.W., Bogue Sandberg, L., Drewek, M.W., o’Bryant, T. L., "Behavior and Modeling of Wood-pegged Timber Frames”, Journal of Structural Engineering ASCE, Vol. 125, No. 1, 1999, pp. 3-9.

[51] Seo, J-M, Choi, I.-K., and Lee, J.-R., "Static and Cyclic Behavior of Wooden Frames with Tenon Joints under Lateral Load”, Journal of Structural Engineering ASCE, Vol. 125, No. 3, 1999, pp. 344-349.

[52] Villar J.R., Guaita M., Vidal P., Arriaga F., "Analysis of the Stress State at the Cogging Joint in Timber Structures”, Biosystems Engineering, Vol. 96, No. 1, 2007, pp. 79-90.

[53] Sangree R.H., Schafer B.W., "Experimental and numerical analysis of a halved and tabled traditional timber scarf joint", Construction and Building Materials, Vol. 23, 2009, pp. 615-624. 
[54] Sangree R.H., Schafer B.W., "Experimental and numerical analysis of a stop-splayed traditional timber scarf joint with key", Construction and Building Materials, Vol. 23, 2009, pp. 376-385.

[55] Parisi M.A., Cordié C., "Mechanical behavior of double-step timber joints", Construction and Building Materials, Vol. 24, 2010, pp. 1364-1371.

[56] Feio A.O., Lourenço P.B., Machado J.S., Testing and modeling of a traditional timber mortise and tenon joint. Materials and Structures, Vol. 47, 2014, pp. 213-225.

[57] Branco J, Descamps T., Analysis and strengthening of carpentry joints, in State of the art report on reinforcement of timber structures, COST Action FP1101, 2014.

[58] King, W. S., Yen, R. J. Y., Yen, A. Y. N, “Joint characteristics of traditional Chinese wooden frames”, Engineering Structures, Vol. 18, No. 8, 1996, pp. 635-644.

[59] Guam, Z., Kitamori, A., Komatsu, K., "Experimental study and finite element modelling of Japanese Nuki joints - Part 1: initial stress state subject to different wedge configurations”, Engineering Structures, Vol. 30, 2008, pp.2032-2040.

[60] Guam, Z., Kitamori, A., Komatsu, K., "Experimental study and finite element modelling of Japanese Nuki joints - Part 2: racking resistance subject to different wedge configurations”, Engineering Structures, Vol. 30, 2008, pp. 2041-2049.

[61] Lam, F., He, M., Yao, C., "Example of Traditional Tall Timber buildings in China - the Yingxian Pagoda”, Structural Engineering International, Vol. 2, 2008, pp. 126-129.

[62] Parisi, M.A., Piazza, M., "Seismic evaluation and strengthening of timber structures in traditional buildings", in: Proceedings of Intl. Conference "250th Anniversary of the Lisbon earthquake”, Lisbon, 2005, pp 451-457.

[63] Piazza, M., Riggio M.P., Tomasi, R., Giongo, I., “Comparison of in-situ and laboratory testing for the characterization of old timber beams before and after intervention", Advanced Materials Research, Vols. 133-134, 2010, pp. 1101-1106.

[64] Riggio, M., Sandak, J., Sandak, A., Piazza, M., “Coupling local semi-destructive techniques and non-destructive imaging for the characterization of traditional timber structures: a case study", in: Proceedings of 5th International Congress "Science and Technology for the Safeguard of Cultural Heritage in the Mediterranean Basin", Vol. II, Istanbul, Turkey, 2011, pp. 8-13.

[65] Riggio, M. P., Tomasi, R., Piazza, M., "Refurbishment of a Traditional Timber Floor with a Reversible Technique: Importance of the Investigation Campaign for Design and Control of the Intervention”, International Journal of Architectural Heritage, Vol. 8, No. 1, 2014, DOI: 10.1080/15583058.2012.670364, pp. 74-93.

[66] Parisi, M. A., Piazza, M., Chesi, C., "Seismic response of traditional timber elements and roof structures: learning from the L'Aquila earthquake”, Paper no. 64, in: Proceedings of SHATIS'11 Intl Conference on Structural Health Assessment of Timber Structures, Lisbon, Portugal, 2011. 